\title{
Characterization of Morphological Diversity of Jute Mallow (Corchorus spp.)
}

\author{
Munguatosha Ngomuo, ${ }^{1}$ Tsvetelina Stoilova, ${ }^{2}$ Tileye Feyissa, ${ }^{1,3}$ and Patrick A. Ndakidemi ${ }^{1}$ \\ ${ }^{1}$ School of Life Sciences, Nelson Mandela African Institution of Science and Technology, P.O. Box 447, Arusha, Tanzania \\ ${ }^{2}$ AVRDC-World Vegetable Center, P.O. Box 10, Arusha, Tanzania \\ ${ }^{3}$ Institute of Biotechnology, Addis Ababa University, P.O. Box 1176, Addis Ababa, Ethiopia
}

Correspondence should be addressed to Munguatosha Ngomuo; ngomuom@nm-aist.ac.tz

Received 10 February 2017; Revised 9 May 2017; Accepted 4 July 2017; Published 8 August 2017

Academic Editor: Cristina Patanè

Copyright (C) 2017 Munguatosha Ngomuo et al. This is an open access article distributed under the Creative Commons Attribution License, which permits unrestricted use, distribution, and reproduction in any medium, provided the original work is properly cited.

Jute mallow is a traditional leaf vegetable that is an important part of daily diet for the majority of people in rural areas in sub-Saharan Africa. Here we employed quantitative and qualitative phenotypic traits to assess the morphological diversity of 90 accessions using univariate and multivariate analyses. Field experiments were conducted for two seasons to identify accessions suitable for leaf yield. The accessions were significantly variable in all traits. Highest variability among accessions was found in harvest index, biomass yield, and weight of 1000 seeds. The traits that significantly correlated with biomass yield include plant height $(r=0.448)$, petiole length $(r=0.237)$, primary branches $(r=0.319)$, and number of leaves per plant $(r=0.333)$. Principal component analysis showed that the first five PCs with eigenvalues $\geq 1$ explained $72.9 \%$ of the total variability in the accessions. Pods per plant, primary branches, secondary branches, and number of leaves per plant accounted for highest variability in PC1. Cluster analysis grouped the accessions into five major clusters mainly based on their origin. Thus, the collection displayed high variation in morphological traits, particularly those related to leaf yield. These accessions are therefore useful in breeding for the improvement of the crop and germplasm management.

\section{Introduction}

Jute mallow (Corchorus spp.) is a very nutritious African traditional vegetable and has been in use in many households [1-4]. The genus Corchorus is comprised of annual or shortlived perennial herbs and shrubs with many agriculturally useful species [5]. It is widely known for its high genetic diversity and geographical distribution and Corchorus olitorius is from Africa [6-9]. The vegetable is extensively grown for the sliminess of the leaves used in local dishes. It is one of the leading leafy vegetables in West Africa [10].

Crop improvement programs on Jute mallow for selection of varieties with finer and high-quality fiber have received considerable attention over the years in Asian countries such as China, Bangladesh, and India [11-13]. However, improvement programs on the Jute mallow as a vegetable, particularly C. olitorius and other wild relatives used as a vegetable in Africa, are very limited $[14,15]$.
Characterization of genetic diversity among accessions of different germplasms by using phenotypic traits is an initial step towards crop improvement [16-18]. The variation in these traits can be used to classify materials into different groups. In Jute mallow, because of variations in local types in traits such as plant height, stem color, pubescence, fruit and leaf shape, and leaf production, Westphal-Stevels [1] proposed a classification of Cameroon materials and other West African countries into three cultivar groups, that is, cv.group Olitorius, cv.-group Incisifolius, and cv.-group Géant de Bertoua, with the main distinguishing feature being leaf shape.

Morphological studies on several accessions have been done in Nigeria to separate segregated populations into different leaf types [19].

Nwangburuka and Denton [14] reported significant differences among fifteen genotypes in terms of morphological traits such as plant height at maturity, number of leaves 
per plant, fresh leaf weight, stem weight, total plant weight, and harvest index. Osawaru et al. [20] used morphological traits and presence of soluble proteins to determine the relationship among three Corchorus species. Traits such as growth habit and stem features appeared to be uniform except for stem color. They also found that determinate growth habit, medium plant branching, and erect stems were the most important traits for production of leaves, which are edible part and are needed by farmers. Nyadanu et al. [15] reported high variability in morphological traits in local cultivars of Ghana. The cultivars were grouped based on their geographical origin and traits such as number of leaves per plant, leaf length, and number of branches per plant were the most informative traits in differentiating the accessions.

Few studies on genetics of leaf yield and its components have been conducted on Jute mallow; however, only few accessions have been used [11, 14, 20]. Benor et al. [9] assessed patterns of morphological variation in Jute mallow accessions of Ethiopian origin and compared them with those from other parts of the world. In their study, samples were collected from Ethiopia and compared with the samples from Asia and Africa. They found high genetic diversity among the African accessions and high similarity between North African accessions and Asian accessions. Accessions from West and Southern Africa and some samples from East Africa were not included in this study. These accessions which may be highly diverse remain unexploited for breeding and improvement of jute mallow vegetable.

The exploitation of existing diversity of characters of each individual accession forms a major principle in plant improvement. Thus, in order to improve leaf yield of Jute mallow, the knowledge required is not only that of the diversity and genetic variability of the available germplasm but also that of genetic architecture of leaf yield and its components.

In view of the above, our study is focused on vegetative, inflorescence, fruit, and seed traits and their contribution towards divergence in these accessions as important step in identifying those which have high yield potential and good adaptation to specific environment.

\section{Materials and Methods}

2.1. Study Location. The experimental field was located at Madiira farm at an altitude of $1262 \mathrm{~m}$ above sea level, latitude $03.38^{\prime} \mathrm{S}$ and longitude $36.87^{\circ} \mathrm{E}$. The soils are well drained. The center experiences annual average rainfall of $1500-1800 \mathrm{~mm}$ and average daily temperature range of $22-27^{\circ} \mathrm{C}$.

2.2. Experimental Design and Layout. The experiments had two phases: first sowing the accessions in the screen house followed by transplanting of seedling to the field. In the screen house the seeds were sown in plastic trays (with 66 holes; diameter of $4 \mathrm{~cm}$ and depth of $4 \mathrm{~cm}$ ) by using sterilized soil. After 28 days, the seedlings were transplanted to the field. Each plot size was $3 \mathrm{~m} \times 0.6 \mathrm{~m}$ with three replications. Each replication contained 90 plots. The plots were arranged according to a completely randomized design. Each accession was planted in two rows, and the space between plants was $0.25 \mathrm{~m}$ with 12 plants per row.
Fertilizer application was done one week after transplanting, where diammonium phosphate (DAP) and urea fertilizers were applied. DAP was applied at a rate of $143.8 \mathrm{kgP} / \mathrm{ha}$ and urea at a rate of $55.2 \mathrm{kgN} / \mathrm{ha}$. The experiments were conducted during the rainfall season; the plants were only supplemented with irrigation when necessary. Manual weeding was carried out when it was necessary to maintain weedfree plots.

2.3. The Experimental Materials. Ninety accessions of Jute mallow (Corchorus spp.) were provided by the seed repository of the World Vegetable Center, Eastern and Southern Africa, for these experiments (Table 1). The experiments were carried out for two growing seasons in 2015 and 2016 (from February to June). Jute mallow collection represents one of the different types of traditional vegetables collected from farmers' field and preserved ex situ for breeding, other research activities, and farmers' purposes.

2.4. Morphological Study. Thirty-three quantitative and qualitative morphological traits were used to estimate the level of variation among the accessions from seedling stage to seed characterization (Table 2). During vegetative growth, measurements of leaves and stem were recorded following Jute mallow descriptor list of WorldVeg [21]. Plant height, flower diameter, and pedicel length together with plant height and plant canopy were measured at flowering. 50\% flowering was recorded for each accession. During maturity stage, data on first mature pod, fruit length, and fruit shape and color were recorded. The number of seeds per pod was counted and weight of 1000 seeds was also measured (Table 2).

2.5. Data Analyses. For quantitative data, descriptive statistics, that is, mean and maximum and minimum values, were calculated followed by analysis of variance (ANOVA). The quantitative characters were plotted on box and whisker plots [22] to reveal the dispersion of data set in different populations. Frequency distribution table was used to describe the qualitative traits. Pearson's simple correlations were used to compare the degrees of association in leaf yield and other traits. The quantitative data were standardized before they were used as an input for PCA and cluster analysis. Descriptive statistics and ANOVA were computed by STATISTICA software version 12, edition 2013 (StatSoft Inc., Tulsa, OK, USA). Multivariate analyses were performed with SAS software.

\section{Results}

3.1. Variation in Qualitative Characters. Fourteen qualitative characters of this study are summarized in a frequency distribution (Table 3). At the seedling stage, three types of cotyledon colors were observed in our studied accessions in which $67 \%$ were light green, $30.9 \%$ were green, and $2.1 \%$ were purplish green. During vegetative growth, green stem color was predominant among the accessions (52\%), while brown and red-purple colors were shared among the remaining accessions (24\% each). Most accessions were characterized by light green and green leaf color. The presence of leaf lobe 
TABLE 1: The list of Jute mallow accessions (Corchorus spp.) used in this study.

\begin{tabular}{|c|c|c|}
\hline SN & Accession name & Country of origin \\
\hline 1 & HS & Tanzania \\
\hline 2 & Bafia & Cameroon \\
\hline 3 & Ex-Chamalawi & Malawi \\
\hline 4 & IP 5 & Kenya \\
\hline 5 & IP10 & Kenya \\
\hline 6 & UG-JM-1 & Uganda \\
\hline 7 & SUD-1 & Sudan \\
\hline 8 & TOT 4879 & USA \\
\hline 9 & ML-JM-1 & Malawi \\
\hline 10 & TOT 5877 & Japan \\
\hline 11 & ES & Tanzania \\
\hline 12 & ML-JM-14 & Malawi \\
\hline 13 & SUD-4 & Sudan \\
\hline 14 & CAMEROON & Cameroon \\
\hline 15 & EX-ZIMBABWE & Zimbabwe \\
\hline 16 & TOT 4064 & Vietnam \\
\hline 17 & ТОТ 0124 & Malaysia \\
\hline 18 & IP-2 & Kenya \\
\hline 19 & Aziga & Cameroon \\
\hline 20 & ML-JM-5 & Malawi \\
\hline 21 & TOT 6426 & Kenya \\
\hline 22 & TOT 5876 & Japan \\
\hline 23 & UG-JM-2 & Uganda \\
\hline 24 & TOT 6278 & Vietnam \\
\hline 25 & SUD-3 & Sudan \\
\hline 26 & UG-JM-13 & Uganda \\
\hline 27 & TOT 4157 & Vietnam \\
\hline 28 & MIX & Tanzania \\
\hline 29 & TOT 4885 & Japan \\
\hline 30 & TOT 5999 & Taiwan \\
\hline 31 & TOT 4429 & Bangladesh \\
\hline 32 & ALV MN 059 & Unknown \\
\hline 33 & KIPUMBULIKO & Unknown \\
\hline 34 & ML-JM-2 & Malawi \\
\hline 35 & TOT 4712 & Bangladesh \\
\hline 36 & IP 1 & Kenya \\
\hline 37 & TOT 4721 & Bangladesh \\
\hline 38 & TOT 7977 & Bangladesh \\
\hline 39 & ML-JM-4 & Malawi \\
\hline 40 & TOT 4541 & Bangladesh \\
\hline 41 & ML-JM-13 & Malawi \\
\hline 42 & UG & Uganda \\
\hline 43 & IP-4 & \\
\hline 44 & GKK 10 & Malawi \\
\hline 45 & CAMEROON MULA & Cameroon \\
\hline 46 & SUD-2 & Sudan \\
\hline 47 & TOT 4316 & Bangladesh \\
\hline 48 & TOT 4097 & Tanzania, Kenya \\
\hline
\end{tabular}

TABle 1: Continued.

\begin{tabular}{|c|c|c|}
\hline SN & Accession name & Country of origin \\
\hline 49 & Local Big Leaves & Mali \\
\hline 50 & GKK 25 & Malawi \\
\hline 51 & ML-JM-12 & Malawi \\
\hline 52 & CAMEROON EX. CO & Cameroon \\
\hline 53 & TOT 4669 & Bangladesh \\
\hline 54 & TOT 4051 & Vietnam \\
\hline 55 & TOT 4312 & Bangladesh \\
\hline 56 & TOT 4352 & Bangladesh \\
\hline 57 & ML-JM-7 & Malawi \\
\hline 58 & TOT 4519 & Bangladesh \\
\hline 59 & TOT 6280 & Vietnam \\
\hline 60 & TOT 4800 & Vietnam \\
\hline 61 & TOT 8975 & Taiwan \\
\hline 62 & TOT 4708 & Bangladesh \\
\hline 63 & TOT 4670 & Bangladesh \\
\hline 64 & TOT 7974 & Bangladesh \\
\hline 65 & TOT 4589 & Bangladesh \\
\hline 66 & TOT 4713 & Bangladesh \\
\hline 67 & TOT 3499 & Vietnam \\
\hline 68 & TOT 4067 & Vietnam \\
\hline 69 & TOT 4631 & Bangladesh \\
\hline 70 & TOT 4500 & Bangladesh \\
\hline 71 & TOT 8532 & Unknown \\
\hline 72 & TOT 6667 & Philippines \\
\hline 73 & ML-JM-9 & Malawi \\
\hline 74 & TOT 6730 & Unknown \\
\hline 75 & TOT 6425 & Uganda \\
\hline 76 & TOT 7980 & Bangladesh \\
\hline 77 & TOT 4413 & Bangladesh \\
\hline 78 & TZA 3070 & Tanzania \\
\hline 79 & TOT 9736 & Unknown \\
\hline 80 & TOT 4624 & Bangladesh \\
\hline 81 & TOT 6749 & Unknown \\
\hline 82 & TOT 4701 & Bangladesh \\
\hline 83 & TOT 4623 & Bangladesh \\
\hline 84 & TOT 7865 & Unknown \\
\hline 85 & TOT 7866 & Unknown \\
\hline 86 & TZA 3002 & Tanzania \\
\hline 89 & TOT 6427 & Kenya \\
\hline 90 & TOT 3584 & Unknown \\
\hline
\end{tabular}

was only observed in $8.5 \%$ of accessions. These accessions were also characterized by palmate leaf shape and cleft leaf margins. The remaining accessions had no leaf lobes. For leaf shape, ovate and cordate leaf shapes were observed in $38.3 \%$ and $35.1 \%$, respectively. Leaf margins and stem pattern displayed little variation; that is, $62.8 \%$ of accessions were coarsely serrate and $87.2 \%$ had erect stems. At maturity stage, among all the accessions, $62.8 \%$ possessed long pods, while 9.5\% had globule fruits and the remaining accessions had round pods. Three types of fruit color were also observed: 
TABLE 2: Qualitative and quantitative traits used in this study.

\begin{tabular}{|c|c|c|}
\hline SN & Character & Description \\
\hline (1) & Plant height $(\mathrm{PH})$ & Height of the plant measured at ground surface at $50 \%$ flowering $(\mathrm{cm})$ \\
\hline (2) & Leaf length (LL) & Leaf blade length excluding petiole length $(\mathrm{cm})$ \\
\hline (3) & Leaf width (LW) & Mature leaf width measured at widest point $(\mathrm{cm})$ \\
\hline (4) & Leaf length-width ratio (LWR) & The ratio of leaf length to leaf width \\
\hline (5) & Petiole length (PL) & Length of leaf stalk $(\mathrm{cm})$ \\
\hline (6) & Days to $50 \%$ flowering (50 FLR) & Number of days from sowing to $50 \%$ flowering \\
\hline (7) & Number of primary branches $(\mathrm{PB})$ & Number of branches from main stem \\
\hline (8) & Number of secondary branches (SB) & Number of branches from the secondary stem \\
\hline (9) & Plant canopy (PC) & Plant width taken at widest point $(\mathrm{cm})$ \\
\hline$(10)$ & Flower diameter (FD) & The width of an open flower (mm) \\
\hline (11) & Pedicel length (PEDL) & The stalk of the flower $(\mathrm{mm})$ \\
\hline (12) & Fruit length (FL) & Length of mature fruit excluding the pedicel \\
\hline (13) & Days to first mature pods (DMP) & Number of days from sowing to first mature pod \\
\hline (14) & Harvest index $(\mathrm{HI})$ & Ratio of total harvestable leaves to total weight of the plant \\
\hline (15) & Number of leaves (NL) & Counted from individual plant during flowering \\
\hline$(16)$ & Biomass yield (BY) & Total weight of the plant above the ground surface (gm) \\
\hline (17) & Number of pods/plant (NPP) & Counted from individual plant at maturity stage \\
\hline (18) & Weight of 1000 seeds (W1000S) & Measured in weighing balance after counting \\
\hline (19) & Seeds per pod (SP) & Counted from individual pod \\
\hline (20) & Cotyledon color (CC) & (3) Light green, (5) green, (7) purplish green \\
\hline (21) & Stem color $(\mathrm{ST})$ & (3) Brown, (5) green, (7) red-purple \\
\hline (22) & Leaf color (LC) & (1) Light green, (3) green, (5) dark green, (7) purple, (9) dark purple \\
\hline (23) & Leaf lobe (LL) & (0)Absent, (1) present \\
\hline$(24)$ & Setae $(S)$ & (1) Small, (2) large \\
\hline (25) & Leaf shape (LS) & (1) Ovate, (3) elliptical, (5) cordate, (7) palmate \\
\hline (26) & Leaf base (LB) & (1) Rounded, (3) sagittate, (5) acute \\
\hline (27) & Leaf apex (LA) & (1) Acuminate, (3) caudate, (5) acute, (7) palmate \\
\hline (28) & Leaf margin (LM) & (1) Coarsely serrate, (3) cleft, (5) double serrate, (7) finely serrate, (9) crenate \\
\hline (29) & Stem pattern $(\mathrm{SP})$ & (1) Erect, (2) semierect \\
\hline$(30)$ & Stipule color (SC) & (1) Green, (3) green stipule with dark red base, (5) light purple \\
\hline$(31)$ & Petiole color (PETC) & (1) Green, (3) green with dark red base, (5) purple \\
\hline$(32)$ & Fruit shape (FS) & (3) Globule, (5) long pod, (7) round pod \\
\hline$(33)$ & Fruit color (FRC) & (3) Pale brown, (5) brown, (7) brown \\
\hline
\end{tabular}

pale brown (67\%), brown (11.7\%), and dark brown (21.3\%). The accessions were also highly variable in terms of stipule color and petiole color.

3.2. Variation in Quantitative Characters. Significant $(p<$ 0.001 ) variation was revealed for vegetative, floral, and seed traits. Harvest index, biomass yield, and weight of 1000 seeds showed highly significant variation (Table 4 ). There was a wide range of values in traits such as numbers of primary and secondary branches, weight of 1000 seeds, number of pods per plant, and number of seeds per pod. Number of days to $50 \%$ flowering varied significantly, ranging from 52 days to 110 days; this grouped the accessions into three categories: early, mid, and late flowering. Days to first mature pod also corresponded to $50 \%$ flowering, which ranged from 73 days to 135 days; thus there were earlier and late maturing accessions in terms of seed yield. Similarly, plant canopy exhibited a wide range resulting from the growth habit of the accessions; some had bushy canopy with many primary and secondary branches, while others had small canopy with few primary and secondary branches. The wide range observed in fruit length from $0.5 \mathrm{~cm}$ to $18.2 \mathrm{~cm}$ is attributed to differences in fruit shapes; the accessions with round pods belong to $C$. capsularis species. They had very small fruit size as compared to $C$. olitorius species. Other traits such as petiole length, leaf length and width, flower diameter, and pedicel length, though had a fairly narrow range, differed significantly $(p<0.001)$ among the accessions, indicating highly significant variation among the accessions.

Box and whisker plots are displayed in Figure 1 for selected quantitative traits. The accessions were divided into seven subpopulations based on their origin. Populations A, B, $\mathrm{C}$, and $\mathrm{E}$ were from Africa, while populations $\mathrm{F}$ and $\mathrm{G}$ were from Asia. In terms of plant height, the highest interquartile 
TABLE 3: Frequency distribution table of qualitative morphological traits.

\begin{tabular}{|c|c|c|c|}
\hline \multicolumn{2}{|l|}{ SN } & Plant traits & Percentage \\
\hline \multirow{3}{*}{ (1) } & \multirow{3}{*}{ Cotyledon color } & Light green & 67 \\
\hline & & Green & 30.90 \\
\hline & & Purplish green & 2.10 \\
\hline \multirow{3}{*}{ (2) } & \multirow{3}{*}{ Stem color } & Brown & 24 \\
\hline & & Green & 52 \\
\hline & & Red-purple & 24 \\
\hline \multirow{5}{*}{ (3) } & \multirow{5}{*}{ Leaf color } & Light green & 38.30 \\
\hline & & Green & 45.70 \\
\hline & & Dark green & 5.30 \\
\hline & & Purple & 8.50 \\
\hline & & Dark purple & 1.10 \\
\hline \multirow{2}{*}{ (4) } & \multirow{2}{*}{ Leaf lobe } & Absent & 91.50 \\
\hline & & Present & 8.50 \\
\hline \multirow{2}{*}{ (5) } & \multirow{2}{*}{ Setae } & Small & 72.30 \\
\hline & & Large & 27.70 \\
\hline \multirow{4}{*}{ (6) } & \multirow{4}{*}{ Leaf shape } & Ovate & 38.30 \\
\hline & & Elliptical & 16 \\
\hline & & Cordate & 35.10 \\
\hline & & Palmate & 8.50 \\
\hline \multirow{3}{*}{ (7) } & \multirow{3}{*}{ Leaf base } & Round & 87.20 \\
\hline & & Sagittate & 6.40 \\
\hline & & Acute & 6.40 \\
\hline \multirow{4}{*}{ (8) } & \multirow{4}{*}{ Leaf apex } & Acuminate & 33 \\
\hline & & Caudate & 10.60 \\
\hline & & Acute & 46.80 \\
\hline & & Palmate & 7.40 \\
\hline \multirow{5}{*}{ (9) } & \multirow{5}{*}{ Leaf margin } & Coarsely serrate & 62.80 \\
\hline & & Cleft & 9.60 \\
\hline & & Double serrate & 13.80 \\
\hline & & Finely serrate & 10.60 \\
\hline & & Crenate & 3.20 \\
\hline \multirow{2}{*}{ (10) } & \multirow{2}{*}{ Stem pattern } & Erect & 87.20 \\
\hline & & Semierect & 12.80 \\
\hline \multirow{3}{*}{ (11) } & \multirow{3}{*}{ Stipule color } & Green & 46.80 \\
\hline & & Green stipule with dark red base & 26.60 \\
\hline & & Light purple & 25.50 \\
\hline \multirow{4}{*}{ (12) } & & Light green & 43.60 \\
\hline & Petiole color & Dark green & 28.70 \\
\hline & & Light purple & 21.30 \\
\hline & & Purple & 5.30 \\
\hline & & Globule & 9.50 \\
\hline (13) & Fruit shape & Long pod & 62.80 \\
\hline & & Round & 27.70 \\
\hline & & Pale brown & 67 \\
\hline (14) & Fruit color & Brown & 11.70 \\
\hline & & Dark brown & 21.30 \\
\hline
\end{tabular}

ranges were observed in a group of accessions originating from Southeast Asia.
All accessions from Africa showed almost the same average plant height irrespective of which part of the continent they originated from. West African and North African accessions had high interquartile ranges for both leaf length and leaf width. Southeast Asian accessions had highest interquartile ranges for number of leaves per plant as compared with the rest of other populations. 50\% flowering period did not vary much across all populations. Harvest index and plant canopy traits indicated high variability among the accessions, which were reflected in leaf yield. The highest plant canopy was observed in accessions from East Africa.

3.3. Simple Correlations. Biomass yield was statistically significant $(p=0.05)$ and positively correlated with plant height $(r=0.448)$, petiole length $(r=0.237)$, primary branches $(r=0.319)$, days to first mature pods $(r=0.306)$, and number of leaves per plant $(r=0.333)$ (Table 5). Harvest index was positively and significantly correlated to leaf width $(r=0.355)$, petiole length $(r=0.310)$, and days to $50 \%$ flowering $(r=0.270)$. It was also negatively correlated with secondary branches $(r=0.350)$. Positive and significant correlation was observed between number of leaves per plant and plant height $(r=0.505)$, petiole length $(r=0.261)$, $50 \%$ flowering $(r=0.378)$, primary and secondary branches $(r=0.577$ and 0.559$)$, pods per plant $(r=0.582)$, and number of days to first mature pods $(r=0.433)$. On the other hand, seed yield components such as number of pods per plant were positively and significantly correlated with plant height $(r=0.357), 50 \%$ flowering $(r=0.307)$, and primary and secondary branches $(r=0.620$ and 0.680$)$. Fruit length was positively correlated to plant canopy $(r=0.378)$ and flower diameter $(r=0.561)$. It was negatively correlated to $50 \%$ flowering and primary and secondary branches. Number of seeds per pod was positively correlated with leaf width $(r=$ $0.307)$, plant canopy $(r=0.271)$, flower diameter $(r=0.694)$, and fruit length $(r=0.658)$.

3.4. Principal Component Analysis. Principal component analysis (PCA) of the 19 quantitative traits is summarized in Table 6. The first five PCs had eigenvalues $>1$ and they explained $72.97 \%$ of the total variation for the morphological traits of the accessions. Numbers of primary and secondary branches, number of pods per plant, and number of leaves per plant loaded highly in PC1 and they accounted for $27.33 \%$ of the total variation of the studied samples.

PC2 accounted for $18.65 \%$ of the total morphological variation among the accessions. Leaf width, petiole length, and days to first mature pods loaded more in PC2. PC3 accounted for $11.81 \%$ of the total variation. Traits such as plant canopy, fruit length, and biomass yield loaded more in PC3. PC4 contributed $9.51 \%$ of the total morphological variation in these accessions with only leaf length and leaf lengthwidth ratio loading highly. PC5 accounted for $5.66 \%$ of total variation with weight of 1000 seeds loading highly. Generally, for the 19 morphological traits studied, PC1 and PC2 constituted $45.9 \%$ of the total morphological variation with most vegetative traits and seeds related traits. This indicated that these traits can be used to classify the accessions under this study. 
TABLE 4: The results of descriptive statistics for quantitative traits.

\begin{tabular}{|c|c|c|c|c|}
\hline SN & Trait & Mean \pm SE & Max. & Min. \\
\hline (1) & Plant height $(\mathrm{cm})$ & $78.08 \pm 0.96^{* *}$ & 137.50 & 52 \\
\hline (2) & Leaf length $(\mathrm{cm})$ & $11.63 \pm 0.15^{* *}$ & 20.97 & 6.50 \\
\hline (3) & Leaf width $(\mathrm{cm})$ & $5.41 \pm 0.07^{* *}$ & 10.05 & 2.73 \\
\hline (4) & Leaf length-width ratio & $2.22 \pm 0.08^{* *}$ & 3.16 & 1.12 \\
\hline (5) & Petiole length $(\mathrm{cm})$ & $4.85 \pm 0.08^{* *}$ & 10.22 & 1.99 \\
\hline (6) & Days to $50 \%$ flowering & $64.93 \pm 0.54^{* *}$ & 110 & 52 \\
\hline (7) & Number of primary branches & $12.16 \pm 0.19^{* *}$ & 21.60 & 1.00 \\
\hline (8) & Number of secondary branches & $15.22 \pm 0.92^{* *}$ & 79.80 & 0 \\
\hline (9) & Plant canopy $(\mathrm{cm})$ & $71.88 \pm 1.18^{* *}$ & 125.10 & 10 \\
\hline (10) & Flower diameter $(\mathrm{mm})$ & $11.22 \pm 0.13^{* *}$ & 15.20 & 5.52 \\
\hline (11) & Pedicel length (mm) & $2.28 \pm 0.03^{* *}$ & 4.22 & 1.14 \\
\hline (12) & Fruit length (cm) & $5.05 \pm 0.13^{* *}$ & 18.20 & 0.50 \\
\hline (13) & Days to first mature pod & $107.60 \pm 0.58^{* *}$ & 135 & 72.50 \\
\hline (14) & Harvest index & $24.08 \pm 0.65^{* * *}$ & 61.35 & 0.90 \\
\hline (15) & Number of leaves & $288.82 \pm 11.41^{* *}$ & 1329 & 15 \\
\hline (16) & Biomass yield & $332.40 \pm 7.62^{* * *}$ & 1001 & 43 \\
\hline (17) & Number of pods/plant & $111.96 \pm 6.48^{* *}$ & 660 & 0 \\
\hline (18) & Weight of 1000 seeds & $1.48 \pm 0.04^{* * *}$ & 4.50 & 1 \\
\hline (19) & Number of seeds per pod & $136.42 \pm 3.69^{* *}$ & 275 & 8 \\
\hline
\end{tabular}

${ }^{* *}$ Significant at $p<0.01 .{ }^{* * *}$ Significant at $p<0.001$.

Three-dimensional principal component analysis showing the relationship among quantitative traits of studied accessions is presented in Figure 2. Accessions from West Africa, East Africa, and North Africa recorded higher values for PC2; traits related to leaves and days to first mature pods were found at the center of PCA scatter plot. Accessions from Asia had higher values for $\mathrm{PC1}$, those related to branching habit, pods per plant, and number of leaves per plant. These accessions were most dispersed and diverse as compared to other accessions.

3.5. Cluster Analysis. Dendrogram for complete linkage cluster analysis of quantitative and qualitative traits is presented in Figure 3. The results indicated that the accessions were grouped into five major clusters. Cluster 1 contained 7 accessions from Bangladesh and Vietnam. These are characterized by stems and leaves that are purple in color and have round pods. Also these accessions had high number of branches (Table 7). Cluster 2 contained 7 accessions from Bangladesh and Vietnam with addition of two accessions from Malaysia and one from Taiwan. These were characterized by both green stems and purple stems and the leaves were green. Accessions in this cluster belong to C. capsularis except three accessions on top of the cluster. They are also characterized by highest plant height compared to all other accessions. Cluster 3 contained 12 accessions: 7 from Bangladesh and Japan, four from unknown origin, and 1 from Kenya. These were classified with semierect stems and few pods and high plant canopy compared with other clusters. All had long pods and belong to species $C$. olitorius. Cluster 4 was the largest one with 33 accessions from almost all countries. These had both erect and semierect stem patterns. Cluster 5 contained 29 accessions: 9 from East and Southern Africa, 8 from Asia, 4 from an unknown origin, 2 from North Africa, and 6 from West Africa. The accessions (8) in the upper cluster are characterized by palmate leaves with cleft margins. The other 10 accessions are characterized by big leaves. In this cluster, accessions such as Bafia and Aziga had globule pods as compared to other accessions which had long and round pods. These had erect stems and have late flowering. Generally, clusters 1 and 2 contained accessions from Asia, while cluster 5 contained accessions from Africa. This grouping pattern indicates their distinct centers of origin and ecological adaptation. Clusters 3 and 4 contained mixed accessions from different countries.

\section{Discussion}

Germplasm collections from underutilized traditional vegetables such as Jute mallow can be an important step in breeding for improvement of the crop [23, 24]. Accessions, particularly those from East and Southern Africa, remain unexploited. The accessions under this study are morphologically very diverse according to the multivariate analysis of both quantitative and qualitative traits. The accessions demonstrated high variation in harvest index, biomass yield, and weight of 1000 seeds. These are important aspects to consider during selection of accessions with high leaf yield. Adebo et al. [7] and Nwangburuka and Denton [14] reported number of leaves per plant, plant height at maturity, and harvest index as discriminating traits among $C$. olitorius accessions. In breeding for leafy vegetable, these materials can be used as parental stock. Variation in primary and secondary branches is an important informative trait in differentiating 

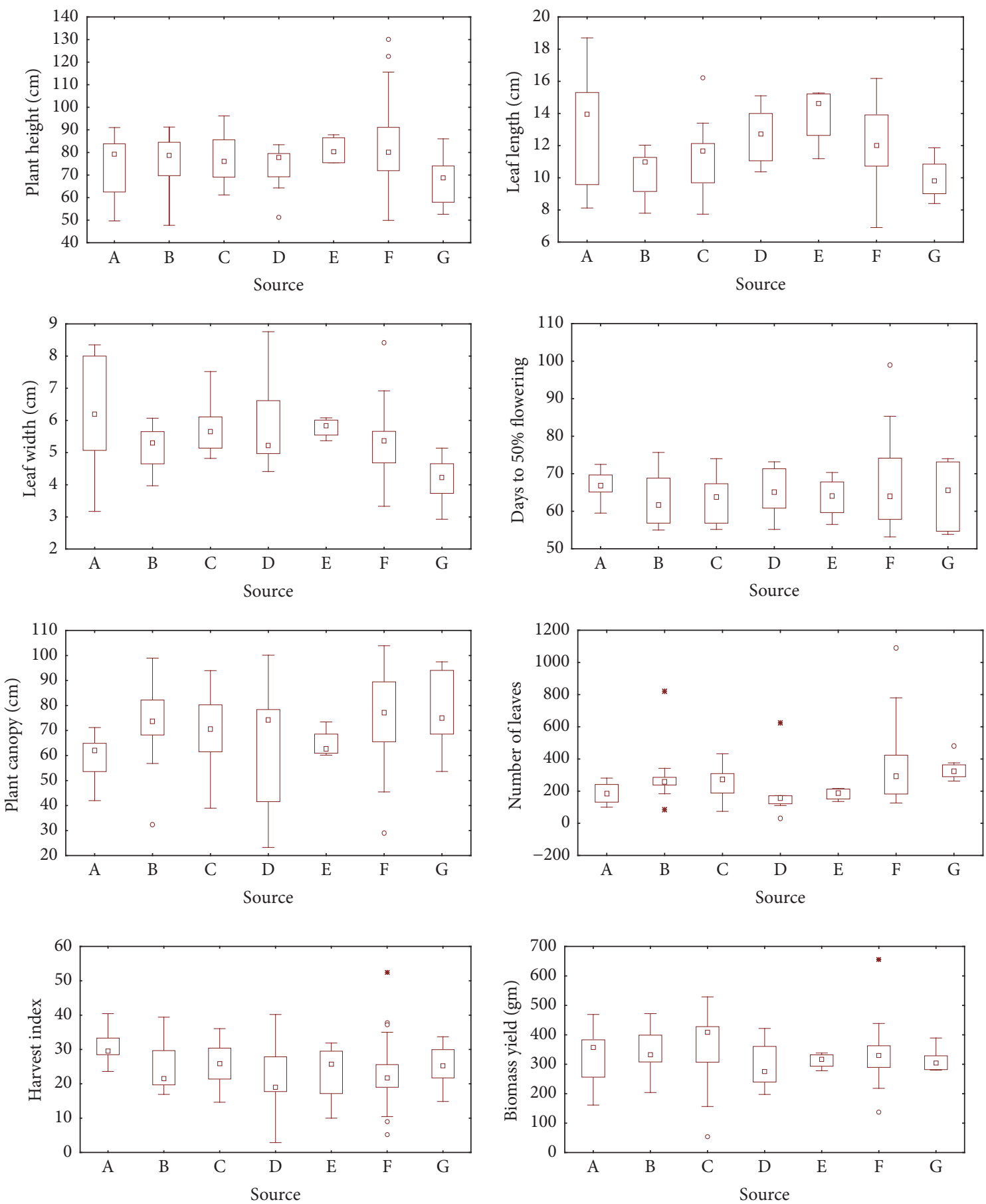

FIGURE 1: Box and whisker plots showing the variation in quantitative traits of the accessions from different parts: (A) West Africa, (B) East Africa, (C) South Africa, (D) unknown, (E) North Africa, (F) Southeast Asia, and (G) East Asia.

accessions, particularly those desirable for leaf production. Accessions from East Africa had high plant canopy, which is a result of high branching habit and large leaves. These traits are attributes of leaf yield. Similar results are reported by Benor et al. [9] and Shukla et al. [25] in Jute mallow and amaranth, respectively. Accessions from East Asia show lowest interquartile ranges for leaf length, leaf width, and number of leaves. This indicates accessions more desirable for fiber than leaf production.

The analysis of simple correlations among the traits revealed that accessions with high plant height, petiole length, and number of primary branches had high biomass yield 


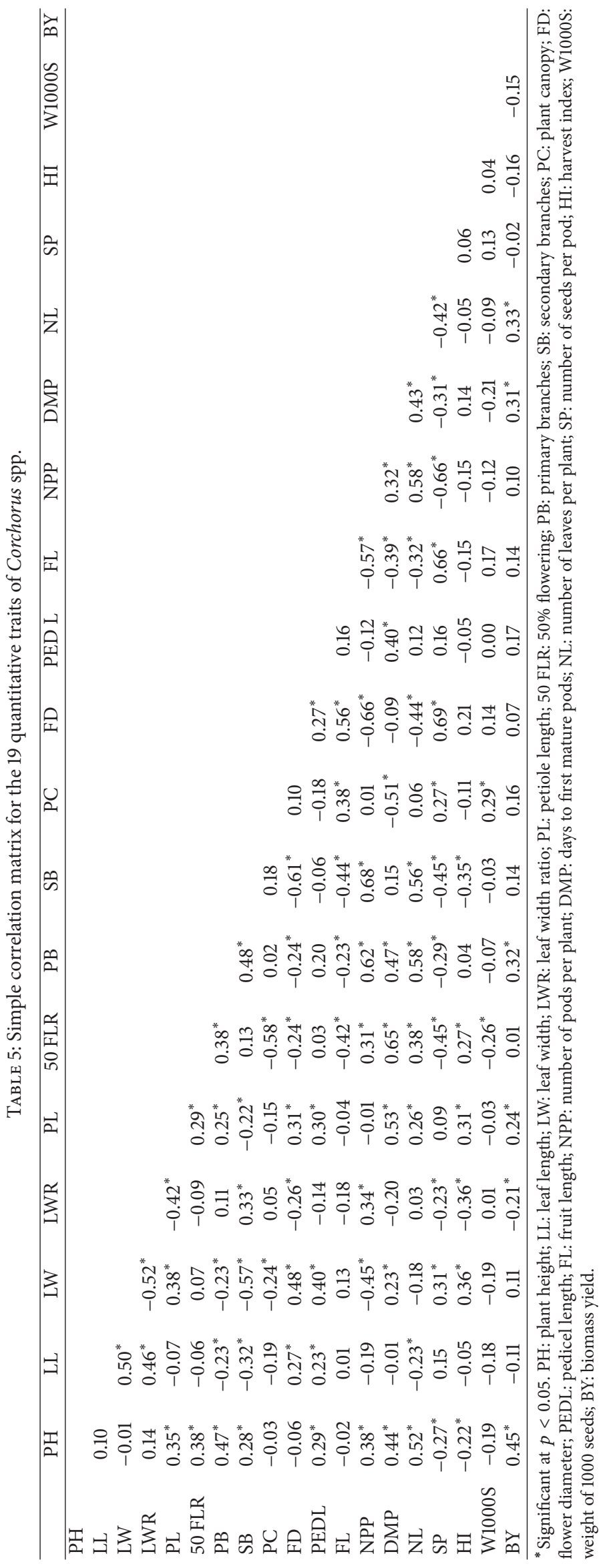


TABLE 6: Eigenvalues, proportion of variance, and morphological traits that contributed to the first five PCs.

\begin{tabular}{|c|c|c|c|c|c|}
\hline Traits & PC1 & PC2 & PC3 & PC4 & PC5 \\
\hline Plant height & 0.22 & 0.19 & 0.28 & 0.28 & -0.02 \\
\hline Leaf length & -0.11 & 0.09 & -0.19 & 0.60 & 0.16 \\
\hline Leaf width & -0.19 & 0.38 & -0.09 & 0.09 & -0.10 \\
\hline LW ratio & 0.12 & -0.28 & -0.08 & 0.48 & 0.31 \\
\hline Petiole length & 0.03 & 0.39 & 0.13 & -0.17 & 0.17 \\
\hline $50 \%$ flowering & 0.24 & 0.27 & -0.24 & -0.07 & 0.01 \\
\hline Primary branches & 0.30 & 0.11 & 0.24 & -0.03 & 0.23 \\
\hline Secondary branches & 0.33 & -0.19 & 0.15 & 0.01 & 0.00 \\
\hline Plant canopy & -0.08 & -0.25 & 0.44 & -0.11 & 0.06 \\
\hline Flower diameter & -0.32 & 0.21 & 0.16 & 0.07 & 0.17 \\
\hline Pedicel length & -0.02 & 0.29 & 0.18 & 0.26 & 0.26 \\
\hline Fruit length & -0.29 & -0.00 & 0.36 & 0.06 & -0.07 \\
\hline Pods per plant & 0.38 & -0.09 & 0.02 & 0.01 & 0.09 \\
\hline Days to first mature pods & 0.23 & 0.38 & -0.04 & 0.02 & 0.06 \\
\hline Number of leaves & 0.33 & 0.09 & 0.22 & -0.06 & 0.03 \\
\hline Seeds per pod & -0.34 & 0.05 & 0.22 & 0.02 & 0.05 \\
\hline Harvest index & -0.07 & 0.22 & -0.22 & -0.39 & 0.25 \\
\hline Weight of 1000 seeds & -0.09 & -0.14 & 0.15 & -0.22 & 0.66 \\
\hline Biomass yield & 0.09 & 0.17 & 0.41 & 0.05 & -0.40 \\
\hline Eigenvalues & 5.19 & 3.54 & 2.24 & 1.81 & 1.08 \\
\hline Proportion variance (\%) & 27.33 & 18.65 & 11.81 & 9.51 & 5.66 \\
\hline Cumulative variance (\%) & 27.33 & 45.98 & 57.79 & 67.30 & 72.97 \\
\hline
\end{tabular}

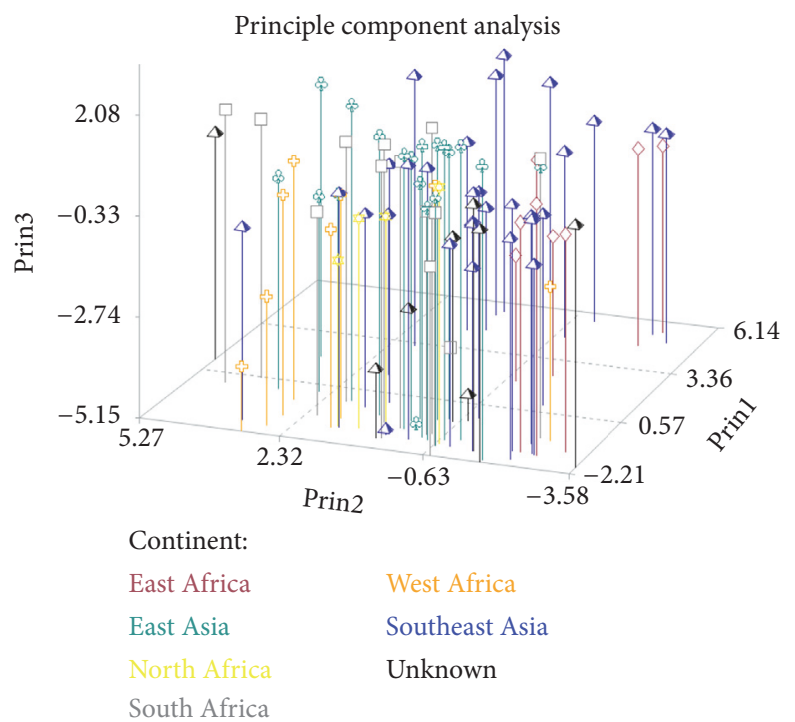

FIGURE 2: Three principle components showing relationship among quantitative traits of studied accessions.

as well as fruits. Positive correlations recorded among the accessions suggest that these traits can be used as selection criteria for accessions with high leaf yield. Plant height was also positively and significantly related to number of days to $50 \%$ flowering. Similar to our study, Ojiewo et al. [26] reported significant correlation between days to $50 \%$ flowering and plant height in lentil. These traits can be transferred to desired accessions through breeding due to high heritability. Positive correlation between harvest index and $50 \%$ flowering is a challenge for leaf harvesting of these accessions. The most limiting and significant factors to leaf production and yield are early and prolific flowering and berry production [27].

Traits such as number of primary branches, pods per plant, and number of leaves per plant accounted for the variations recorded in the accessions in PC1. Similar to our study, Nyadanu et al. [15] reported leaf length and numbers of branches per plant and leaves per plant as traits that defined $\mathrm{PCl}$ in their study. On the other hand, leaf width, days to first mature pods, and petiole length accounted for the variation observed in the accessions in PC2. Total cumulative variance was $45.98 \%$, indicating the high degree of diversity among the traits under study. Furthermore, the traits can be used as phenotypic markers in differentiating the accessions.

Cluster analysis grouped the accessions into five clusters. Clusters 1 and 2 contained accessions from Asia only. These accessions are from $C$. capsularis species. Few numbers of branches (5-8 branches), high plant height, and low number of leaves characterized these accessions (Figure 2). This is attributed to unique selection pressure that aimed to improve fiber yield. Palit et al. [11] reported greater homogeneity in accessions from Asia, which was due to uniformity in selection pressure from commercial considerations. It is interesting that one accession from East Africa clustered with accessions from Asia. This pattern of clustering indicates, on one hand, the diversity of population within these geographical areas and, on the other hand, similarity of 


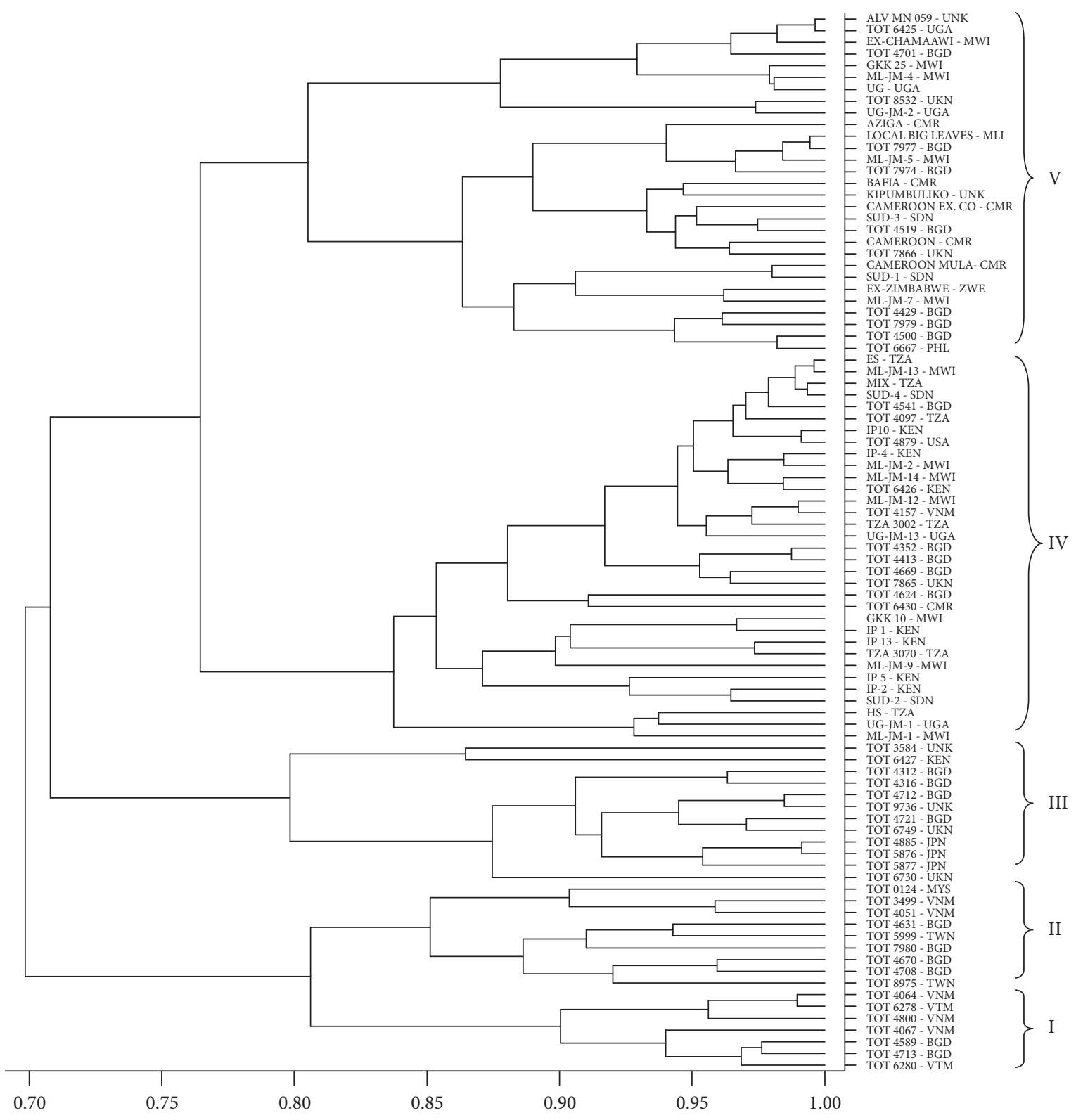

FIGURE 3: Dendrogram of 90 accessions of Corchorus spp. explained by complete linkage clustering of 19 quantitative traits and 14 qualitative traits. The source of accessions is indicated by the country code of respective accession and UKN represents unknown accession.

accessions from different geographical areas. These results agree with the report of Alemayehu and Becker [28] in Brassica carinata. This is due to some level of similarity in other quantitative traits, though the accession belongs to C. olitorius species. Cluster 4 contained mixed accessions from all countries under study. Twenty-five out of thirtythree accessions were from Africa; the remaining accessions from Asia and USA indicate frequent exchange of germplasm across the countries [29]. Similarly, cluster 5 contained most accessions from Africa, a clustering pattern that indicates the distinct nature of the accessions. Most of these accessions were from East and Southern Africa. Some materials with uncertain origin appeared in clusters 3,4 , and 5. However, the origins of the accessions can be traced through their clustering pattern. Generally, the clustering of all accessions in our study indicates significant difference in diversity among their origins as most of Asian accessions are clustered at lower part of dendrogram, that is, clusters 1, 2, and 3. Accessions from Africa are mostly found in the upper part of the dendrogram, that is, clusters 4 and 5 .

\section{Conclusion}

Morphological diversity studies on leaf vegetable Jute mallow (Corchorus spp.) were carried out in 90 accessions. The results from ANOVA, simple correlations, and multivariate analyses indicated high variation among the studied materials. Significant and positive correlation between biomass yield and other 
TABLE 7: Cluster analysis for 19 quantitative traits of Corchorus spp. accessions.

\begin{tabular}{|c|c|c|c|c|c|}
\hline Traits & $\mathrm{C} 1$ & $\mathrm{C} 2$ & $\mathrm{C} 3$ & $\mathrm{C} 4$ & C5 \\
\hline Plant height & 83.51 & 98.50 & 63.88 & 76.43 & 78.38 \\
\hline Leaf length & 10.38 & 11.36 & 10.60 & 11.24 & 12.85 \\
\hline Leaf width & 3.94 & 4.63 & 4.96 & 5.16 & 6.43 \\
\hline LW ratio & 2.70 & 2.48 & 2.18 & 2.22 & 2.04 \\
\hline Petiole length & 4.70 & 4.36 & 3.45 & 4.74 & 5.75 \\
\hline $50 \%$ flowering & 72.79 & 75.28 & 62.21 & 59.73 & 67.20 \\
\hline Primary branches & 16.81 & 14.06 & 9.22 & 11.95 & 11.92 \\
\hline Secondary branches & 37.18 & 33.26 & 10.10 & 14.28 & 7.03 \\
\hline Plant canopy & 73.10 & 57.98 & 73.59 & 79.77 & 65.30 \\
\hline Flower diameter & 7.49 & 8.28 & 10.29 & 11.96 & 12.63 \\
\hline Pedicel length & 1.85 & 2.48 & 1.93 & 2.32 & 2.44 \\
\hline Fruit length & 2.13 & 4.01 & 5.32 & 5.97 & 4.95 \\
\hline Pods per plant & 351.38 & 222.41 & 74.60 & 77.70 & 74.29 \\
\hline Day to first mature pod & 112.48 & 116.48 & 99.44 & 103.69 & 111.65 \\
\hline Number of leaves & 502.85 & 505.12 & 182.66 & 245.00 & 264.49 \\
\hline Seeds per pod & 29.88 & 50.69 & 134.95 & 166.32 & 155.23 \\
\hline Harvest index & 28.47 & 15.65 & 23.85 & 22.94 & 28.33 \\
\hline Weight of 1000 seeds & 1.55 & 1.06 & 1.38 & 1.62 & 1.49 \\
\hline Biomass yield & 344.29 & 377.27 & 250.29 & 347.56 & 332.24 \\
\hline
\end{tabular}

leaf yield-related attributes indicates the potential of using these accessions for improvement of foliage yield. Traits such as plant height, primary branches, and number of leaves per plant proved to be superior in contributing to biomass yield. Based on biomass yield and harvest index traits, accessions Aziga, TOT 8532, UG-JM-13, UG-JM-2, GKK 25, TOT 7980, ML-JM-1, UG-JM-1, Local Big Leaves, and Ex-Chamalawi had highest yields and could be used as potential parental lines for improvement of leaf yield. On the other hand, principal component analysis showed that the variations observed in the accessions are mainly caused by traits such as number of leaves per plant, petiole length, leaf width, days to first mature pods, and branching habit, indicating that their contribution was important in discriminating the accessions. Cluster analysis grouped the accessions based on their origin into five clusters that showed high diversity for most of the traits, demonstrating the homogeneity of accessions from specific location, except for cluster 4 . This clustering pattern can be exploited for identification of highly diverse accessions falling in different clusters for future genetic improvement of this crop. Direct selection can also be made for the accessions with high harvest index and biomass yield based on the recorded performance of these accessions during the field experiments. These results can further be confirmed by molecular diversity analysis, as it has been confirmed by other studies using different materials. In our study, the accessions from this germplasm showed another allele diversity that has remained unexploited for improvement of this vegetable. Therefore, plant breeders can use these germplasms for improvement of Jute mallow.

\section{Conflicts of Interest}

The authors declare that they have no conflicts of interest.

\section{Authors' Contributions}

All the authors collaborated in this work. Munguatosha Ngomuo designed the study and carried out the field work under the supervision of Tsvetelina Stoilova, Tileye Feyissa, and Patrick A. Ndakidemi. Munguatosha Ngomuo and Tsvetelina Stoilova wrote the first draft and contributed to editing, formatting, and statistical analysis. The final draft was read and approved by all the authors.

\section{Acknowledgments}

This research was funded by the Nelson Mandela African Institution of Science and Technology through scholarship funds from the Government of Tanzania. Seed samples of germplasm accessions and experimental site for this study were kindly provided by World Vegetable Center, Eastern and Southern Africa.

\section{References}

[1] J. Westphal-Stevels, "Local vegetables in cameroon:corchorus species used as a vegetable," Acta Horticulturae, vol. 182, pp. 423-426, 1986.

[2] G. Krebs, "Tiliaceae," in Mansfeld's Encyclopedia of Agricultural and Horticultural Crops, P. Hanelt, Ed., vol. 3, pp. 1560-1567, Institute of Plant Genetics and Crop Plant Research, 2001. 
[3] J. Kinabo, A. P. Mnkeni, C. N. M. Nyaruhucha, J. Msuya, A. Haug, and J. Ishengoma, "Feeding frequency and nutrient content of foods commonly consumed in the Iringa and Morogoro regions in Tanzania," International Journal of Food Sciences and Nutrition, vol. 57, no. 1-2, pp. 9-17, 2006.

[4] D. Nyadanu and S. T. Lowor, "Promoting competitiveness of neglected and underutilized crop species: comparative analysis of nutritional composition of indigenous and exotic leafy and fruit vegetables in Ghana," Genetic Resources and Crop Evolution, vol. 62, no. 1, pp. 131-140, 2014.

[5] S. Benor, F. R. Blattner, S. Demissew, and K. Hammer, "Collection and ethnobotanical investigation of Corchorus species in Ethiopia: Potential leafy vegetables for dry regions," Genetic Resources and Crop Evolution, vol. 57, no. 2, pp. 293-306, 2010.

[6] S. Benor, J. Fuchs, and F. R. Blattner, "Genome size variation in Corchorus olitorius (Malvaceae s.l.) and its correlation with elevation and phenotypic traits," Genome, vol. 54, no. 7, pp. 575585, 2011.

[7] H. Adebo, L. Ahoton, F. Quenum, and V. Ezin, "Agromorphological Characterization of Corchorus olitorius Cultivars of Benin," Annual Research \& Review in Biology, vol. 7, no. 4, pp. 229-240, 2015.

[8] B. Kundu, "Origin of jute," Indian Journal of Plant Breeding, vol. 11, pp. 95-99, 1951.

[9] S. Benor, S. Demissew, K. Hammer, and F. R. Blattner, "Genetic diversity and relationships in Corchorus olitorius (Malvaceae s.l.) inferred from molecular and morphological data," Genetic Resources and Crop Evolution, vol. 59, no. 6, pp. 1125-1146, 2012.

[10] G. J. Grubben, "Tropical vegetables and their genetic resources (No. 635 G7)," 1977.

[11] P. Palit, B. C. Sasmal, and A. C. Bhattacharryya, "Germplasm diversity and estimate of genetic advance of four morphophysiological traits in a world collection of jute," Euphytica, vol. 90, no. 1, pp. 49-58, 1996.

[12] B. B. Das and S. N. Maiti, "Jute (Corchorus species) and allied fibres research in India," Indian Journal of Agricultural Sciences, vol. 68 , no. $8,1998$.

[13] S. Palve, M. M, and K. Sinha, "Genetic variation and interrelationships among fibre yield attributes in secondary gene pool of Corchorus spp," SABRAO Journal of Breeding and Genetics, vol. 37, no. 1, pp. 55-64, 2005.

[14] C. C. Nwangburuka and O. A. Denton, "Heritability, character association and genetic advance in six agronomic and yield related characters in leaf Corchorus olitorius," International Journal of Agricultural Research, vol. 7, no. 7, pp. 367-375, 2012.

[15] D. Nyadanu, R. Adu Amoah, A. O. Kwarteng et al., "Domestication of jute mallow (Corchorus olitorius L.): ethnobotany, production constraints and phenomics of local cultivars in Ghana," Genetic Resources and Crop Evolution, vol. 63, pp. 1-17, 2016.

[16] C. C. Julia, D. L. E. Waters, R. H. Wood, and T. J. Rose, "Morphological characterisation of Australian ex situ wild rice accessions and potential for identifying novel sources of tolerance to phosphorus deficiency," Genetic Resources and Crop Evolution, vol. 63, no. 2, pp. 327-337, 2016.

[17] G. Peratoner, S. Seling, C. Klotz, C. Florian, U. Figl, and A. O. Schmitt, "Variation of agronomic and qualitative traits and local adaptation of mountain landraces of winter rye (Secale cereale L.) from Val Venosta/Vinschgau (South Tyrol)," Genetic Resources and Crop Evolution, vol. 63, no. 2, pp. 261-273, 2016.
[18] M. Loumerem and A. Alercia, "Descriptors for jute (Corchorus olitorius L.)," Genetic Resources and Crop Evolution, vol. 63, no. 7, pp. 1103-1111, 2016.

[19] National Horticultural Research Institute, Advances in Fruit and Vegetable Research at NIHORT (1976-1986): A Commemorative Publication to Mark the 10th Anniversary of the National Horticultural Research Institute, NIHORT, Ibadan, Nigeria, 1986.

[20] M. Osawaru, M. Ogwu, A. Chime, and A. Amorighoye, "Morphological Evaluation and Protein Profiling of Three Accessions of Nigerian Corchorus Linn. Species," Bayero Journal of Pure and Applied Sciences, vol. 5, no. 1, pp. 26-32, 2012.

[21] AVRDC, Genetic Resources and Seed Unit (GRSU). Characterization records sheets, AVRDC-The World Vegetable Center, Shanhua, Taiwan, 2008.

[22] J. W. Tukey, Exploratory Data Analysis, Addison-Wesley, Reading, Mass, USA, 1977.

[23] R. Andini, S. Yoshida, Y. Yoshida, and R. Ohsawa, "Amaranthus genetic resources in Indonesia: Morphological and protein content assessment in comparison with worldwide amaranths," Genetic Resources and Crop Evolution, vol. 60, no. 7, pp. 21152128, 2013.

[24] R. L. Nelson, "Managing self-pollinated germplasm collections to maximize utilization," Plant Genetic Resources: Characterisation and Utilisation, vol. 9, no. 1, pp. 123-133, 2011.

[25] S. Shukla, A. Bhargava, A. Chatterjee, A. Srivastava, and S. P. Singh, "Genotypic variability in vegetable amaranth (Amaranthus tricolor L.) for foliage yield and its contributing traits over successive cuttings and years," Euphytica, vol. 151, no. 1, pp. 103110, 2006.

[26] O. C. Ojiewo, N. G. Mwai, O. M. Abukutsa-Onyango, G. S. Agong, and R. Nono-Womdim, "Exploiting the genetic diversity of vegetable African nightshades," Bioremediation, Biodiversity and Bioavailability, vol. 7, no. 1, pp. 6-13, 2012.

[27] S. Shukla, A. Bhargava, A. Chatterjee, A. C. Pandey, and B. K. Mishra, "Diversity in phenotypic and nutritional traits in vegetable amaranth (Amaranthus tricolor), a nutritionally underutilised crop," Journal of the Science of Food and Agriculture, vol. 90, no. 1, pp. 139-144, 2010.

[28] N. Alemayehu and H. Becker, "Genotypic diversity and patterns of variation in a germplasm material of Ethiopian mustard (Brassica carinata A. Braun)," Genetic Resources and Crop Evolution, vol. 49, no. 6, pp. 573-582, 2002.

[29] J. M. Edmonds, Herbarium survey of African Corchorus L. species, IBPGR, Rome, italy, 1990. 


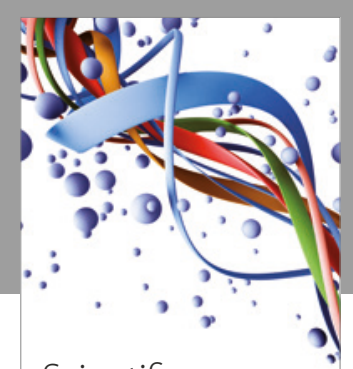

Scientifica
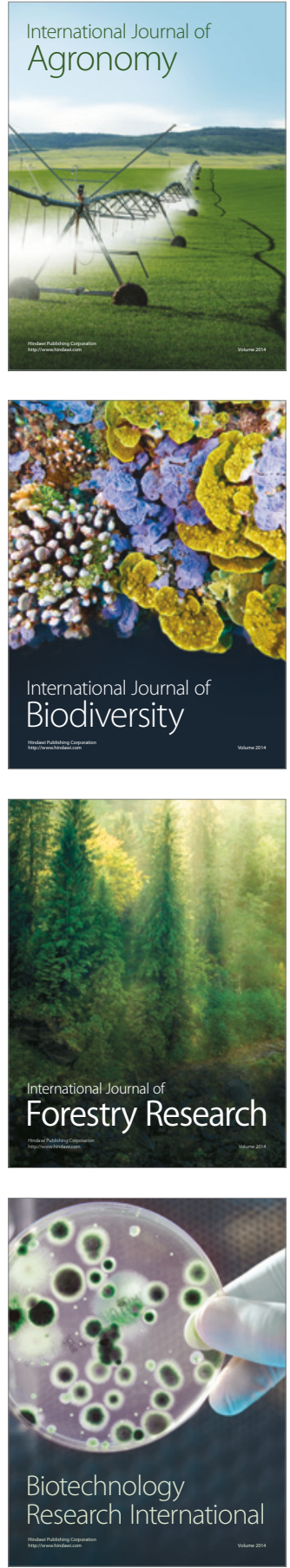
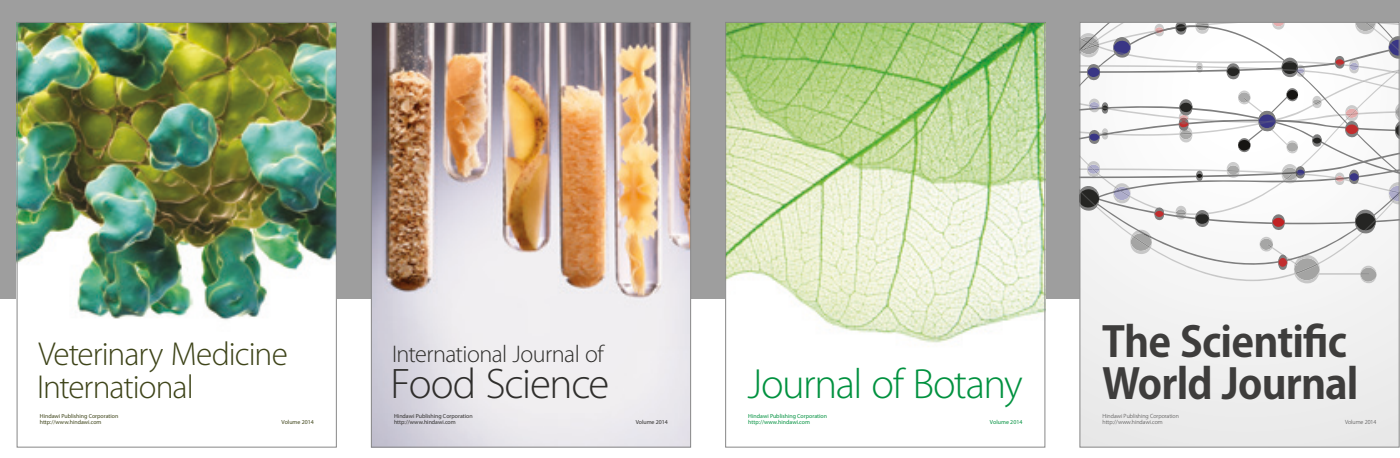

The Scientific

\section{World Journal}

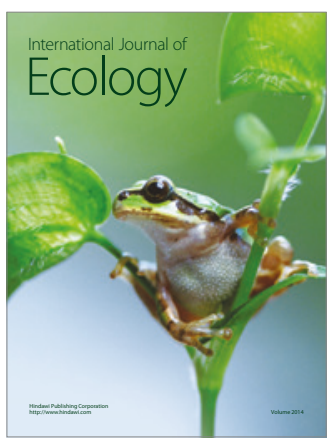

\section{Hindawi}

Submit your manuscripts at

https://www.hindawi.com
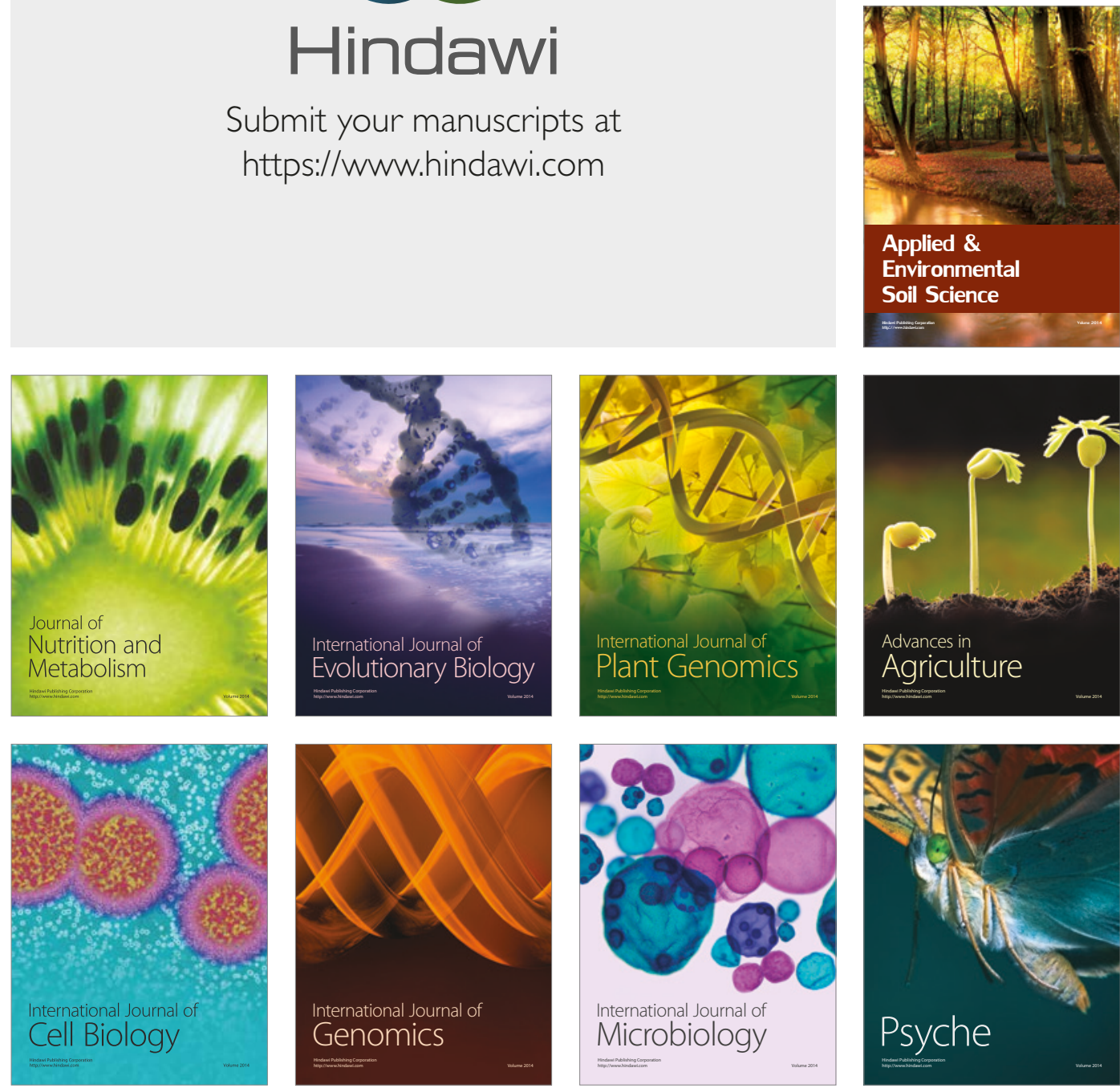

hternational Journal of Microbiology
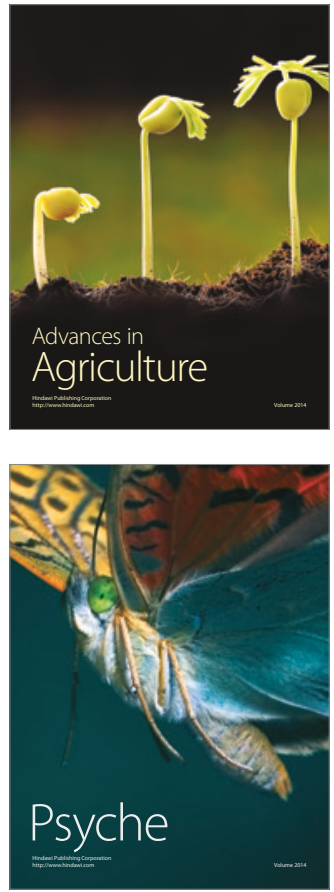